\title{
The histone deacetylase inhibitor trichostatin A downregulates human MDRI (ABCBI) gene expression by a transcription-dependent mechanism in a drug-resistant small cell lung carcinoma cell line model
}

\author{
V El-Khoury', G Breuzard', N Fourré' and J Dufer",I \\ 'Unité MéDIAN-CNRS UMR 6142, IFR 53, Faculté de Pharmacie, Université de Reims Champagne-Ardenne, F-5 096 Reims, France
}

Tumour drug-resistant $A B C B /$ gene expression is regulated at the chromatin level through epigenetic mechanisms. We examined the effects of the histone deacetylase inhibitor trichostatin $A$ (TSA) on $A B C B$ / gene expression in small cell lung carcinoma (SCLC) drugsensitive (H69WT) or etoposide-resistant (H69VP) cells. We found that TSA induced an increase in ABCBI expression in drugsensitive cells, but strongly decreased it in drug-resistant cells. These up- and downregulations occurred at the transcriptional level. Protein synthesis inhibition reduced these modulations, but did not completely suppress them. Differential temporal patterns of histone acetylation were observed at the $A B C B$ / promoter: increase in $\mathrm{H} 4$ acetylation in both cell lines, but different $\mathrm{H} 3$ acetylation with a progressive increase in H69WT cells but a transient one in H69VP cells. $A B C B /$ regulations were not related with the methylation status of the promoter -50GC, - IIOGC, and Inr sites, and did not result in further changes to these methylation profiles. Trichostatin A treatment did not modify MBDI binding to the $A B C B$ / promoter and similarly increased PCAF binding in both $\mathrm{H} 69$ cell lines. Our results suggest that in $\mathrm{H} 69$ drug-resistant SCLC cell line TSA induces downregulation of $A B C B /$ expression through a transcriptional mechanism, independently of promoter methylation, and MBDI or PCAF recruitment.

British Journal of Cancer (2007) 97, 562-573. doi:I0.I038/sj.bjc.66039|4 www.bjcancer.com

Published online 3I July 2007

(c) 2007 Cancer Research UK

Keywords: trichostatin A; epigenetics; drug resistance

The overexpression of the $A B C B 1$ (MDR1) gene product Pglycoprotein (P-gp) has been identified as an important mediator of multidrug resistance (MDR) to chemotherapeutic agents, which can lead to increased tumour resistance and worse prognosis in cancer patients (Gottesman, 2002; Longley and Johnston, 2005).

Small cell lung carcinoma (SCLC) is usually responsive to chemotherapy, but long-term survival is rare. Several chemotherapeutic agents active in SCLC patients (as doxorubicin, etoposide, or vincristine) are P-gp substrates, raising the question of the impact of $A B C B 1$ expression in these types of tumours. In patient samples, good correlations have been reported between increased $A B C B 1$ expression, lack of response to chemotherapy, and shorter survival (Holzmayer et al, 1992; Poupon et al, 1993; Savaraj et al, 1997), suggesting that $A B C B 1$ gene expression may play a significant role in drug resistance in SCLC.

Considerable progress has been made towards the definition of the regulatory mechanisms that control the expression of $A B C B 1$ gene in tumour cells (for review, see Labialle et al, 2002; Scotto, 2003). The $A B C B 1$ promoter lacks a TATA box and contains an initiator element (Inr) necessary for its transcription. Like most TATA-less promoters, $A B C B 1$ promoter contains an inverted

*Correspondence: Professor J Dufer; E-mail: jean.dufer@univ-reims.fr Received 22 March 2007; revised 26 June 2007; accepted 5 July 2007; published online 3I July 2007
CCAAT box (Y box) close to a -50GC box. These two elements, where NF-Y, Sp1, and Sp3 factors can bind, form an enhancesome and recruit the histone acetyltransferase (HAT) PCAF. This HAT further acetylates histones at the proximal promoter region and then induces transcriptional activation of $A B C B 1$ gene. Several other elements have also been described among which a $-110 \mathrm{GC}$ box able to bind a repressor factor. Accessibility of $A B C B 1$ promoter elements to their binding factors is regulated at the chromatin level by epigenetic regulatory mechanisms including DNA methylation and histones post-translational modifications. Among these modifications, acetylation of lysine residues of histone tails by HAT has been correlated with transcriptional activity, whereas deacetylation mediated by histone deacetylases (HDACs) has been associated with gene silencing (Grunstein, 1997; Berger, 2002).

Histone deacetylase inhibitors have been shown to have antitumour effects and a number of them are currently being evaluated in cancer therapy, either alone or in combination with conventional cytotoxic therapy (Yoo and Jones, 2006). In this regard, the impact of HDAC inhibition on $A B C B 1$ gene expression seems to be of critical importance.

We and others showed previously that HDAC inhibition induced similar proliferation inhibition and apoptotic response in $\mathrm{H} 69$ drug-sensitive and drug-resistant cells. This was associated with a blockade of the cells in the $G_{0} / G_{1}$ and the $G_{2} / M$ phases of the cycle in both cell lines (Tsurutani et al, 2003; El-Khoury et al, 2004). 
However, this inhibition induced very different morphological consequences at the chromatin condensation level in drugsensitive and drug-resistant cells (El-Khoury et al, 2004). Such data could raise questions on the effects of HDAC inhibition on $A B C B 1$ expression in these cell variants.

In this study, we have utilised the HDAC inhibitor, trichostatin A (TSA), to investigate the responsiveness of endogenous $A B C B 1$ gene to acetylation states in SCLC H69 cells, either sensitive (H69WT) or resistant to etoposide (H69VP). This response was analysed in terms of dependence on transcription, DNA methylation, or histone acetylation at the promoter level. Moreover, the role of transcription regulators as PCAF and MBD1 was also evaluated.

\section{MATERIALS AND METHODS}

\section{Chemicals}

The HDAC inhibitors TSA and sodium butyrate $(\mathrm{NaB})$, actinomycin D (ActD), and cycloheximide (CHX) were purchased from Sigma-Aldrich (St Quentin-Fallavier, France). All antibodies against histones and peroxidase-conjugated anti-rabbit secondary antibody were from Upstate Biotechnology (Lake Placid, NY). Phycoerythrin-conjugated antibody against P-gp (15D3-PE) was purchased from BD Biosciences (Grenoble, France), anti-PCAF antibody from Santa Cruz Biotechnology (Santa Cruz, CA, USA), and anti-MBD1 antibody from Abcam (Cambridge, UK). All other chemicals were obtained from standard sources.

\section{Cells}

The human small cell lung carcinoma (SCLC) cell line H69 was obtained from ATCC (HTB-119) and its P-gp-positive multidrugresistant variant H69VP selected with etoposide was provided by Professor Maxwell Sehested (Rigshospitalet, Copenhagen, Denmark) (Brock et al, 1995). The two cell lines were grown as previously reported (El-Khoury et al, 2004). The H69VP cells are about 17 -fold resistant to etoposide and 8-fold and 6-fold crossresistant to vincristine and doxorubicin, respectively.

\section{Anti-P-gp immunostaining and fluorescence-activated cell sorting (FACS) analysis}

Cells were stained with phycoerythrin-conjugated anti-P-gp monoclonal antibody 15D3-PE according to the manufacturer's instructions. A total of $2 \times 10^{4}$ cells were immediately analysed on a FACSCalibur flow cytometer (Becton Dickinson, San Jose, CA, USA) with an argon laser set at $488 \mathrm{~nm}$. Data were analysed with BD Cell Quest software.

\section{Real-time and classical reverse transcription (RT) - PCR}

Total cellular RNA was prepared using the guanidine thiocyanate/ phenol method (Tri Reagent, Sigma). RNA ( $1 \mu \mathrm{g})$ was reverse transcribed into cDNA in a final volume of $20 \mu \mathrm{l}$ using the ImProm-II Reverse Transcription System Kit (Promega, WS). Real-time PCR was performed with QuantiTectSYBR-Green PCR Kit (Qiagen, Courtaboeuf, France) on the LightCycler system (Roche Diagnostics, Basel, Switzerland) following the recommendation of the manufacturer. The expression levels of $A B C B 1 \mathrm{mRNA}$ were normalised against $18 \mathrm{~S}$ ribosomal RNA level of the same sample. To detect WTH3 gene expression, classical RT-PCR was carried out using recombinant Taq polymerase (Invitrogen, France) on a PCR System Thermal Cycler (Eppendorf, France) and its expression level was normalised against glyceraldehyde-3phosphate dehydrogenase $(G A P D H)$ mRNA. PCR primers and conditions are available upon request. Values reported represent the mean gene expression from at least three separate experiments \pm s.e.m. Data were analysed using Student's $t$-test.

\section{Acid extraction and immunoblotting of histones}

Histones acid extraction and immunoblotting analysis were performed as described previously (El-Khoury et al, 2004). Antibodies were used at the following dilutions: anti-histone $\mathrm{H} 3$ (1:2000), anti-acetylated histone $\mathrm{H} 3(1: 20000)$, anti-acetylated histone $\mathrm{H} 4(1: 2000)$, and anti-dimethylated histone $\mathrm{H} 3$ on lysine 9 (H3K9) $(1: 2000)$, peroxidase-conjugated anti-rabbit secondary antibody $(1: 2000)$.

\section{Acetic acid-urea-triton (AUT) gel electrophoresis}

Acetic acid-urea-triton gel electrophoresis of histones was carried out following the protocol described previously (El-Khoury et al, 2004).

\section{Chromatin immunoprecipitation (ChIP) assay}

The ChIP assay kit from Upstate Biotechnology was used following the manufacturer's instructions with the following modifications: cross-linking with formaldehyde was carried out for 10-20 min. Chromatin was immunoprecipitated with $8 \mu \mathrm{g}$ of either antiacetylated histone $\mathrm{H} 3$, anti-acetylated histone $\mathrm{H} 4$, anti-dimethylated H3K9, anti-PCAF, or with $15 \mu \mathrm{l}$ of anti-MBD1 antibody. Three regions of the $A B C B 1$ promoter were analysed: a proximal region $(+292$ to +591$)$, a distal region $(-981$ to -817$)$, and the inverted CCAAT box (Y box) region $(-222$ to +37$)$. In the case of histones and PCAF analyses, PCR products were resolved on $2 \%$ agarose gels stained with ethidium bromide, and quantitated using Typhoon 9210 scanner and Image Quant analysis software (Amersham Biosciences, Orsay, France). For MBD1 analysis, real-time PCR was carried out. PCR primers and conditions are available upon request.

\section{Bisulphite treatment of genomic DNA and methylation- specific PCR}

Genomic DNA was isolated using NucleoSpin Tissue kit (Macherey-Nagel, Hoerdt, France) according to manufacturer's protocol. A total of $2 \mu \mathrm{g}$ of genomic DNA was denatured in $0.3 \mathrm{moll}^{-1} \mathrm{NaOH}$ for $15 \mathrm{~min}$ at $37^{\circ} \mathrm{C}$. The denaturated DNA was incubated with $0.5 \mathrm{~mm}$ hydroquinone and $3.1 \mathrm{moll}^{-1}$ sodium bisulphite $(\mathrm{pH} 5)$ for $16 \mathrm{~h}$ at $50^{\circ} \mathrm{C}$. DNA was purified using the Wizard DNA clean-up system (Promega) and desulphonated with $0.3 \mathrm{~N} \mathrm{NaOH}$ at $37^{\circ} \mathrm{C}$ for 15 min. DNA was precipitated with ammonium acetate and ethanol, washed with $70 \%$ ethanol, and resuspended in $20 \mu \mathrm{l}$ distilled water. For methylation-specific PCR analysis, the bisulphite-modified DNA samples were amplified by primers specific for both methylated and unmethylated sequences of the $-50 \mathrm{GC}$ and $-110 \mathrm{GC}$ boxes of the $A B C B 1$ promoter. DNA amounts were demonstrated in a PCR analysis using a primer set designed to amplify both the bisulphite-modified methylated and unmethylated sequences of the region including $-50 \mathrm{GC}$ and $-110 \mathrm{GC}$ boxes. PCR primers and conditions are available upon request. PCR products were analysed in $2 \%$ agarose gel stained with ethidium bromide.

\section{Combined bisulphite restriction analysis (COBRA)}

This method enables a quantitative analysis of methylation at specific gene loci (Xiong and Laird, 1997). Bisulphite-modified genomic DNA was amplified by PCR. PCR primers sequences of the Inr region $(-20$ to +172$)$ and PCR conditions are available upon request. Purified PCR products ( $192 \mathrm{bp}$ ) were digested with restriction enzyme TaqI (Invitrogen), which recognises the TCGA 
palindromic sequence unique to the bisulphite-converted DNA of the methylated alleles of the Inr site. DNA samples were precipitated and electrophoresed in $2.5 \%$ agarose gel stained with ethidium bromide. The intensity of methylated alleles was calculated by densitometry using Typhoon 9210 scanner and Image Quant analysis software (Amersham Biosciences).

\section{RESULTS}

\section{TSA and $\mathrm{NaB}$ induce $A B C B 1$ upregulation in H69WT-sensitive cells but downregulation in H69VP-resistant cells}

Several studies indicate that $A B C B 1$ gene activity is regulated by HDACs. To analyse this regulation in drug-sensitive and drugresistant cells, H69WT and H69VP cells were exposed to the HDAC inhibitors TSA and $\mathrm{NaB}\left(330 \mathrm{nmoll}^{-1}\right.$ and $5 \mathrm{mmoll}^{-1}$ concentrations, respectively) for up to $24 \mathrm{~h}$. These concentrations were shown previously optimal for inhibition of HDACs with minimal toxicity in these particular cells (El-Khoury et al, 2004). Trichostatin $\mathrm{A}$ and $\mathrm{NaB}$ induce significant increases in $A B C B 1$ expression in H69WT cells whose basal expression was extremely low (Figure 1A, left). This expression appears as early as $8 \mathrm{~h}$ of treatment with both drugs (56-fold increase with TSA, $P=0.0005$; 35 -fold increase with $\mathrm{NaB}, P=0.008)$ and increases after $24 \mathrm{~h}$ of treatment (164-fold increase with TSA, $P=0.008$; 167 -fold increase with $\mathrm{NaB}, P=0.008)$. On the contrary, TSA and $\mathrm{NaB}$ induce a very significant decrease in $A B C B 1$ expression in H69VP drug-resistant cells (Figure 1A, right). Significant changes can be noted after $8 \mathrm{~h}$ of treatment $(52 \%$ inhibition with TSA, $P<0.0001 ; 59 \%$ inhibition with $\mathrm{NaB}, P=0.0003)$ and $24 \mathrm{~h}$ of treatment with both drugs $(87 \%$ inhibition with TSA, $P<0.0001 ; 83 \%$ inhibition with $\mathrm{NaB}$, $P=0.0001)$. P-glycoprotein expression on cell membranes was analysed by flow cytometry on TSA-treated cells. H69WT and H69VP cells were incubated with or without $330 \mathrm{nmoll}^{-1}$ TSA for $12 \mathrm{~h}$ and left for a further $48 \mathrm{~h}$ period in TSA-free medium. This TSA treatment does not result in significant changes in P-gp expression in H69WT cells (98\% negative cells in TSA-treated or -untreated cells), whereas a decrease in this expression is observed in H69VP cells (Figure 1B), either when data are expressed as percent of P-gp-positive cells $(76 \%+$ ve cells in control cells, $55 \%$ + ve cells in the presence of TSA) or as mean fluorescence index in these positive cells (39 vs 29 respectively), suggesting that $A B C B 1$ gene silencing observed in these drug-resistant cells after TSA treatment could effectively result in inhibition of $\mathrm{P}$-gp expression at the cell membrane level.

\section{TSA-induced $A B C B 1$ modulation occurs at a transcriptional level}

To investigate the mechanisms implicated in these up- or downregulations, we first addressed the question whether ABCB1 expression is directly regulated by TSA in H69 cells. To this end, H69WT and H69VP cells were pretreated for $1 \mathrm{~h}$ with the protein synthesis inhibitor CHX at $10 \mu \mathrm{g} \mathrm{ml}^{-1}$ followed or not by treatment with $330 \mathrm{nmoll}^{-1}$ TSA for $24 \mathrm{~h}$. Cycloheximide alone increased ABCB1 mRNA levels in both H69WT and H69VP cells (7-fold increase, $P=0.002$, and 1.5 -fold increase, $P=0.02$, respectively) (Figure $2 \mathrm{~A}$ and $\mathrm{B}$ ). When TSA was added, $A B C B 1$ mRNA modulation still occurred in both H69WT and H69VP cells in the presence of $\mathrm{CHX}$. However, $\mathrm{CHX}$ induced a partial but significant inhibition of these modulations (Figure 2C). Thus,
A

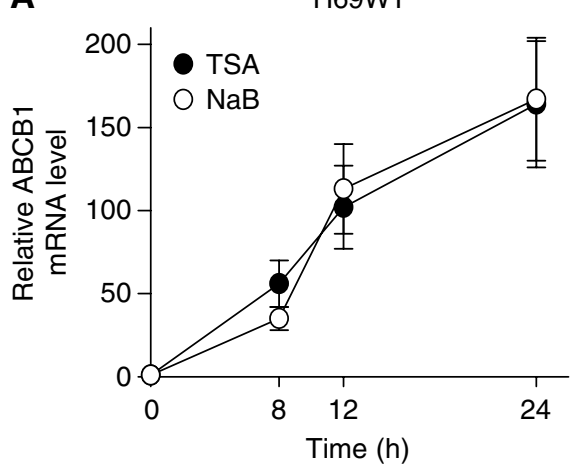

B

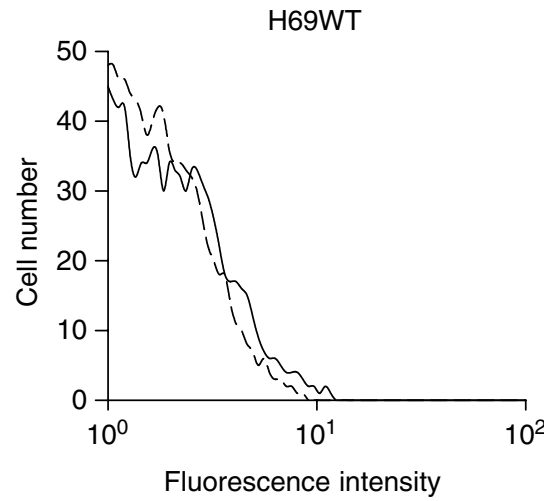

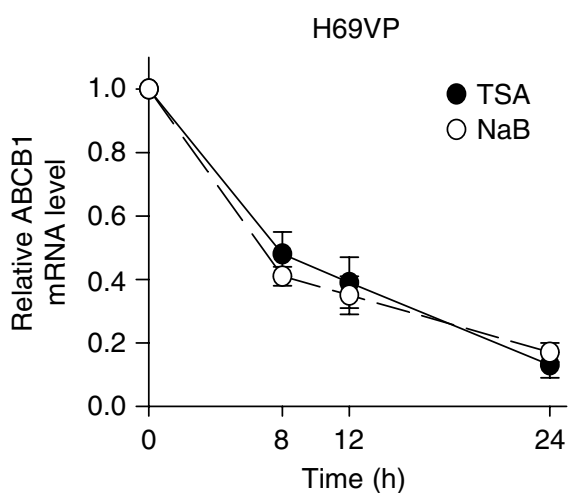

H69VP

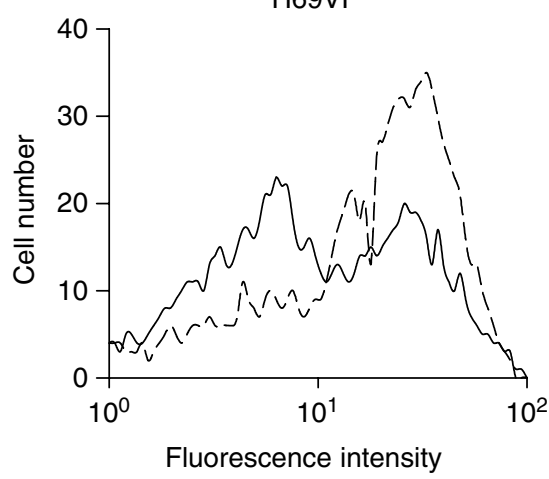

Figure I Trichostatin A (TSA) effects on ABCB I gene in $\mathrm{H} 69$ cells. (A) ABCB I expression in H69WT (left) and H69VP (right) cells treated with TSA $\left(330 \mathrm{nmoll}^{-1}\right)$ or sodium butyrate $\left(\mathrm{NaB}, 5 \mathrm{mmol} \mathrm{I}^{-1}\right)$ for 8,12 , and $24 \mathrm{~h}$. (B) Decrease in P-gp membrane expression in H69VP cells treated with TSA Fluorescence-activated cell sorting analysis was performed with I5D3-PE antibody on H69WT and H69VP cells treated or not with TSA. Dashed line, control cells; solid line, TSA-treated cells. ABCB I expression was normalised against I8S RNA expression (A). Quantitation of the relative changes in gene expression was measured by real time RT-PCR (mean \pm s.e.m. of 3-6 independent experiments). 
A

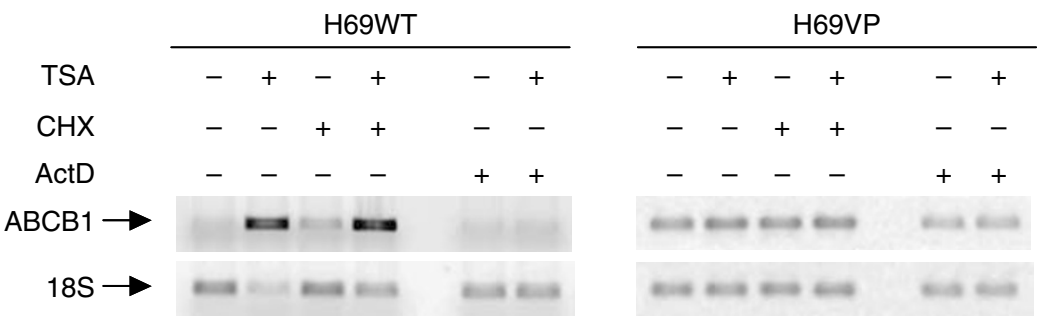

B

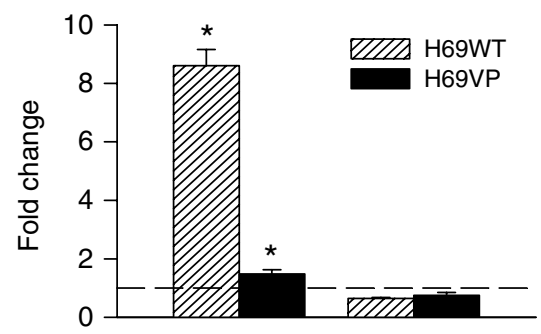

(+) $\mathrm{CHX} \quad(+)$ ActD
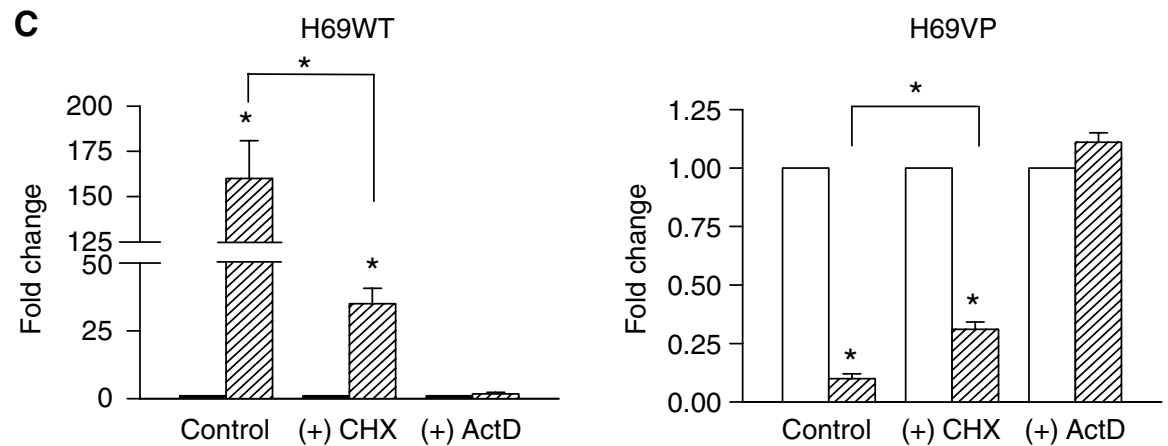

D

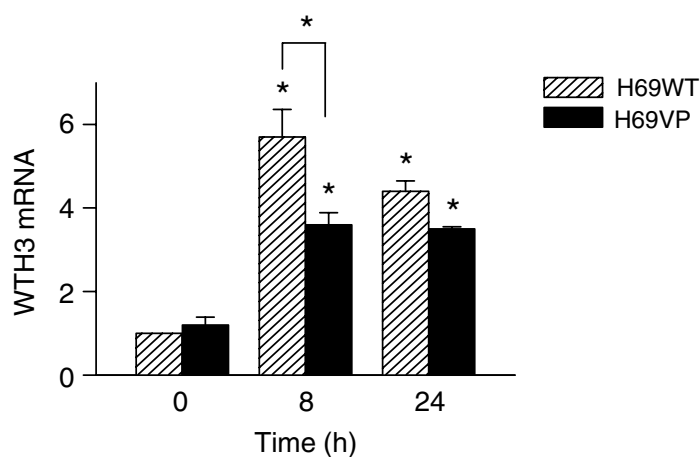

Figure $2 A B C B /$ up- or downregulation by trichostatin $A(T S A)$ occurs through a transcription-dependent mechanism. $(\mathbf{A})$ Expression of $A B C B$ I in cells in presence of TSA, cycloheximide $(\mathrm{CHX})$, or actinomycin D (ActD). Cells were pretreated with $\mathrm{CHX}\left(10 \mu \mathrm{g} \mathrm{ml}{ }^{-1}, \mid \mathrm{h}\right)$ or $\mathrm{ActD}\left(5 \mu \mathrm{g} \mathrm{ml} \mathrm{l}^{-1}, 30 \mathrm{~min}\right)$ before incubation in the presence or absence of TSA $\left(330 \mathrm{nmol}^{-1}, 24 \mathrm{~h}\right)$. PCR reactions were interrupted in the exponential phase and PCR products were electrophoresed in 2.5\% agarose gel stained with ethidium bromide. (B) Expression of ABCBI in cells treated with CHX or ActD alone. H69WT and H69VP cells were incubated in presence or absence of $\mathrm{CHX}\left(10 \mu \mathrm{g} \mathrm{ml}^{-1}\right.$, I h) or ActD $\left(\left.5 \mu \mathrm{g} \mathrm{ml}\right|^{-1}, 30 \mathrm{~min}\right)$. (C) Quantitation of $A B C B /$ expression changes in cells treated with TSA (hatched bars) or not (open bars) in the presence or absence of CHX or ActD. Cells were treated as in (A). (D) WTH3 expression in $\mathrm{H} 69$ cells treated with TSA ( $330 \mathrm{nmol}^{-1}$ ). ABCB I expression was normalised against I8S RNA expression. Quantitation of the relative changes in $A B C B$ I expression was measured by real time RT-PCR. WTH3 expression was normalised against GAPDH RNA expression. Relative changes in WTH3 expression were measured by classical RT-PCR (mean \pm s.e.m. of three independent experiments). ${ }^{*} P<0.05$.

de novo protein synthesis enhances but is not responsible for TSA effect on $A B C B 1$ expression. These results suggest that TSA modulates $A B C B 1$ expression by a direct effect on chromatin, possibly by promoting recruitment of a repressor factor to $A B C B 1$ promoter, as well as through the modulation of regulatory proteins expression. Among these, WTH3 was reported to play a negative role in $A B C B 1$ gene expression. Moreover, WTH3 gene expression seemed to be regulated by epigenetic mechanisms (Tian et al,
2005). However, TSA induced an overexpression of WTH3 in both cell lines with a more important increase in drug-sensitive cells where $A B C B 1$ expression was upregulated (Figure 2D). These results suggest that WTH3 was probably not a key element in TSAinduced $A B C B 1$ inhibition in H69VP cells. To analyse the effects of TSA on $A B C B 1$ transcription, H69WT and H69VP cells were incubated with the RNA synthesis inhibitor ActD at $5 \mu \mathrm{g} \mathrm{ml}^{-1}$ for $30 \mathrm{~min}$ before TSA treatment $\left(330 \mathrm{nmoll}^{-1}\right.$ for $\left.24 \mathrm{~h}\right)$. 
Pre-incubation with ActD completely inhibited TSA effects on $A B C B 1$ expression in H69WT and H69VP cells (Figure 2A and C). These data suggest that TSA regulates $A B C B 1$ expression at the transcriptional level. However, regulation of mRNA abundance can also occur at the level of RNA degradation. To examine if modifications of RNA stability could also account for TSA effects on $A B C B 1$ mRNA levels, H69WT and H69VP cells were pretreated with ActD at $5 \mu \mathrm{g} \mathrm{ml}^{-1}$ to block new RNA synthesis. Then, the cells were treated or not with $330 \mathrm{nmoll}^{-1}$ TSA. ABCB1 mRNA half-lives appeared almost identical in both H69WT and H69VP cells, and TSA treatment did not significantly change these mRNA stabilities (Figure $3 \mathrm{~A}$ and $\mathrm{B}$ ). Finally, we examined if TSA could change $A B C B 1$ mRNA degradation through transcriptional modulation of other genes implicated in mRNA stability. For this purpose, H69WT and H69VP cells were incubated with or without $330 \mathrm{nmoll}^{-1}$ TSA for $6 \mathrm{~h}$ before ActD treatment for $30 \mathrm{~min}$ at $5 \mu \mathrm{g} \mathrm{ml}^{-1}$. ABCB1 mRNA was then analysed immediately and $12 \mathrm{~h}$ later. $A B C B 1$ mRNA level decreased of about $40 \%$ after $12 \mathrm{~h}$ in H69WT cells, whether or not they were pre-incubated with TSA. Similar decreases of about 30\% were observed in H69VP cells (Figure $3 \mathrm{C}$ ). Thus, TSA modulates $A B C B 1$ mRNA transcription both in H69WT and H69VP cells without influencing its degradation.

\section{TSA increases the overall acetylation of histones but} differentially modulates $\mathrm{H} 3$ and $\mathrm{H} 4$ acetylation levels at the $A B C B 1$ promoter level in sensitive and resistant cells

The biological consequence of HDACs inhibition is the accumulation of acetylated histones. To verify the activity of TSA in our study, H69WT and H69VP cells were treated with $330 \mathrm{nmoll}^{-1}$ TSA for up to $24 \mathrm{~h}$, and histones were analysed by AUTpolyacrylamide gel electrophoresis (PAGE) (Figure 4A). The main changes observed, both in H69WT and H69VP cells, were an increase in $\mathrm{H} 4$ and $\mathrm{H} 3$ acetylation, particularly at the $\mathrm{H} 3.3$ and $\mathrm{H} 3.2$ levels, together with an increase in $\mathrm{H} 2 \mathrm{~A}$ and $\mathrm{H} 2 \mathrm{~B}$ acetylation. On the contrary, $\mathrm{H} 1$ remains unaffected by TSA, as this histone form cannot be acetylated through post-translational processes in vivo (Alvelo-Ceron et al, 2000). To confirm these data, the acetylated histone $\mathrm{H} 3$, acetylated histone $\mathrm{H} 4$ and methylated $\mathrm{H} 3 \mathrm{~K} 9$ levels were determined by western blotting. Consistent with previous observations, we found that TSA increased the acetylated histone $\mathrm{H} 3$ and $\mathrm{H} 4$ without any change in methylated $\mathrm{H} 3 \mathrm{~K} 9$ in both H69WT and H69VP cells (Figure 4B). To further analyse the implications of these histone acetylation changes on $A B C B 1$ expression, we performed ChIP assays to determine histone acetylation within specific regions of the $A B C B 1$ promoter. Primer sets encompassing $A B C B 1$ proximal $(+292$ to +591$)$ and distal ( -981 to -817$)$ promoter regions were used to map changes in histone acetylation following TSA treatment. In comparison with H69WT drug-sensitive cells in which the $A B C B 1$ gene is underexpressed, H69VP drug-resistant cells had increased $\mathrm{H} 4$ acetylation in both regions (about twofold) and increased H3 acetylation (about 2.5-fold) in the proximal region of the promoter. H3K9 methylation levels appeared similar in H69WT and H69VP cells (Figure 5A). Following TSA treatment at $330 \mathrm{nmoll}^{-1}$ for up to $24 \mathrm{~h}, \mathrm{H} 4$ acetylation progressively increased at both promoter regions in the two cell lines (Figure 5B). The increase in $\mathrm{H} 4$ acetylation levels was lower in the resistant cells, probably due to the basal hyperacetylation of histone $\mathrm{H} 4$ in these cells at both promoter regions (Figure 5A). An increased $\mathrm{H} 3$ acetylation was also observed in H69WT cells. However, in H69VP cells, TSA induced an only transient $\mathrm{H} 3$ hyperacetylation, with a 2- to 4-fold increase after $8 \mathrm{~h}$ treatment and a return towards basal levels after $24 \mathrm{~h}$ (Figure 5C). If we consider the fold difference in basal H3 acetylation between drug-sensitive and drug-resistant cells (about 2.5 -fold in the proximal region and no difference in the distal region), we can notice that histones $\mathrm{H} 3$ in H69VP drug-resistant cells are approximately twice as hyperacetylated as in H69WT drug-sensitive cells after $8 \mathrm{~h}$ treatment with TSA. The histone H3 deacetylation after $24 \mathrm{~h}$ treatment was not observed by western blotting of total nuclear histone $\mathrm{H} 3$ (Figure 4B), suggesting that this phenomenon remains localised. Trichostatin A treatment did not modify $\mathrm{H} 3 \mathrm{~K} 9$ methylation status at both promoter sites in H69WT or H69VP cells (Figure 5D). These results show that, as expected, the transcriptional activation of $A B C B 1$ induced by TSA in H69WT drug-sensitive cells was associated with hyperacetylation of histones $\mathrm{H} 3$ and $\mathrm{H} 4$ at $A B C B 1$ promoter. On the contrary, hyperacetylation of histones $\mathrm{H} 3$ and $\mathrm{H} 4$ observed in H69VP drugresistant cells after $8 \mathrm{~h}$ treatment with TSA was associated with $A B C B 1$ gene silencing (Figure $1 \mathrm{~A}$ ).

\section{$A B C B 1$ repression by TSA appears independent of DNA methylation status and MBD1 recruitment in H69VP cells}

$A B C B 1$ expression has been shown to be regulated not only by histone acetylation, but also by DNA methylation. $A B C B 1$ promoter contains several GC boxes, which appear essential for
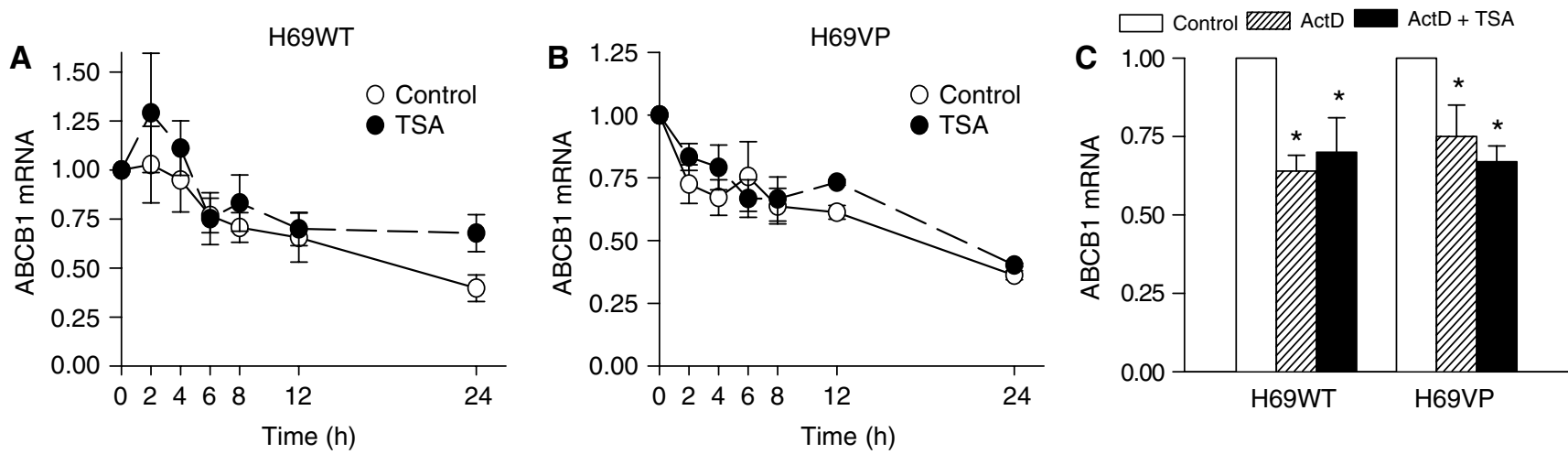

Figure $3 A B C B$ / up-or downregulation by trichostatin $A(T S A)$ is not mediated by mRNA stability changes. (A) Analysis of a transcription-independent TSA effect on $A B C B /$ mRNA stability in $\mathrm{H} 69$ WT cells. Cells were treated with $5 \mu \mathrm{g} \mathrm{m} l^{-1}$ actinomycin D (ActD) 30 min before the addition of $330 \mathrm{nmol} \mathrm{I}^{-}$ TSA. Cells were harvested immediately or as indicated. (B) Analysis of a transcription-independent TSA effect on ABCB I mRNA stability in H69VP cells. Cells were treated and harvested as in (A). (C) Analysis of a transcription-dependent TSA effect on ABCB I mRNA stability. H69WT and H69VP cells were pretreated with $330 \mathrm{nmol}^{-1}$ TSA for $6 \mathrm{~h}$ before the addition of ActD $\left(5 \mu \mathrm{g} \mathrm{ml} l^{-1}, 30 \mathrm{~min}\right)$. Cells were harvested immediately or I $2 \mathrm{~h}$ later for $A B C B / \mathrm{mRNA}$ quantitation. $A B C B /$ expression was normalised against I8S RNA expression. Quantitation of the relative changes in $A B C B /$ expression was measured by real time RT-PCR (mean \pm s.e.m. of three independent experiments). $* P<0.05$. 
A

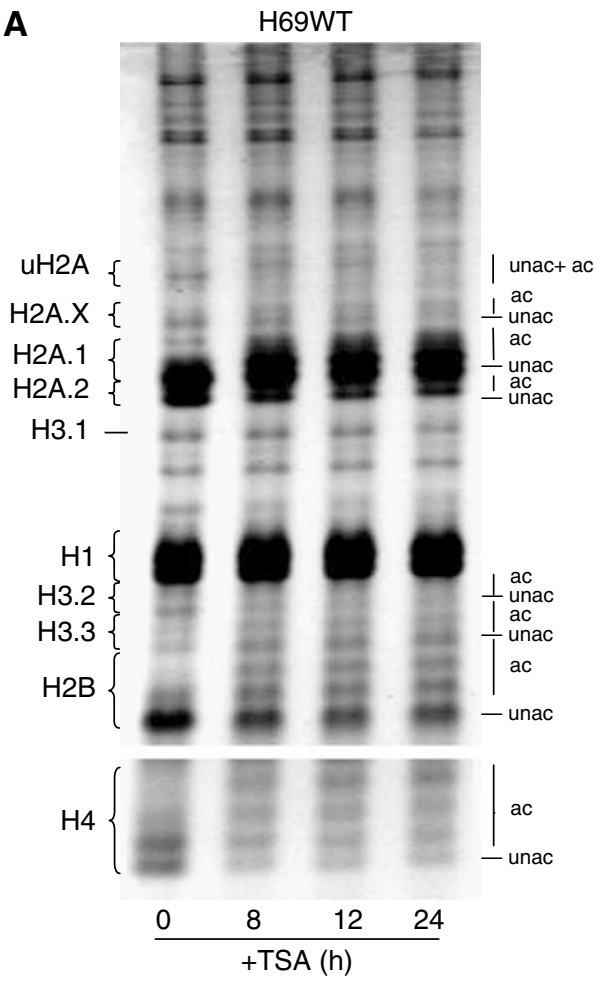

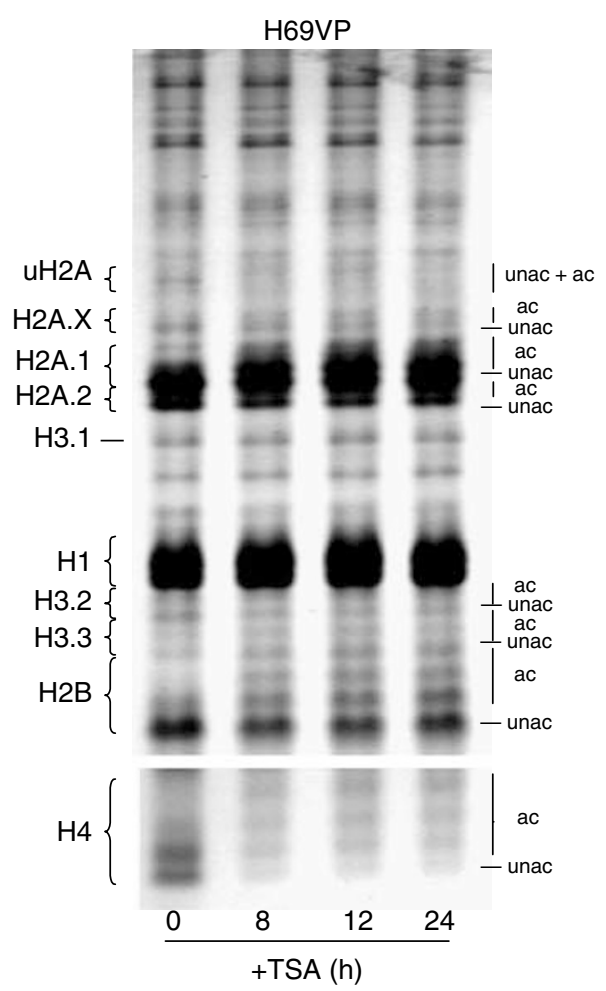

B

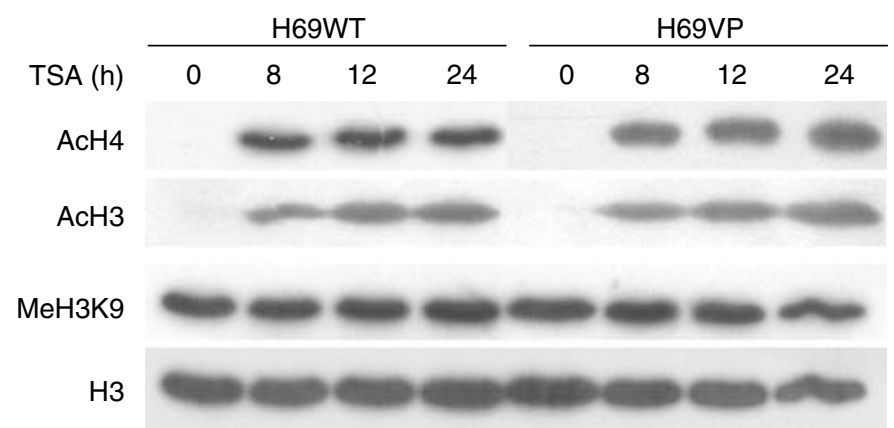

Figure 4 Trichostatin A (TSA) induces global histone acetylation. (A) Acetic acid-urea-triton-polyacrylamide gel electrophoresis of histones extracted from H69WT and H69VP nuclei. (B) Western blot analysis of acetylated H4, acetylated H3, and dimethylated H3K9 levels in nuclear acid extracts from H69WT and H69VP cells. Total histone H3 was used as a loading control.

its activation. Among these, the $-50 \mathrm{GC}$ and $-110 \mathrm{GC}$ boxes appear highly relevant as they seem to be binding sites for $A B C B 1$ activators and repressors. The methylation profiles of these two boxes have been analysed by methylation-specific PCR in H69WT and H69VP cells and compared with those from hypermethylated (MCF7 cells) or hypomethylated (peripheral blood mononuclear cells, PBMCs) controls. The $-50 \mathrm{GC}$ and $-110 \mathrm{GC}$ boxes appeared hypomethylated in both cell lines (Figure 6A). This hypomethylation of $A B C B 1$ promoter was confirmed by a COBRA analysis of the +4 cytosine-phosphate-guanine $(\mathrm{CpG})$ site of the Inr region. Both cell lines appeared to display hypomethylated $A B C B 1$ DNA (Figure 6B). These data confirm the sensitivity of hypomethylated $A B C B 1$ promoter to the direct action of HDACs (El-Osta et al, 2002). Treatment of H69WT and H69VP by TSA $\left(330 \mathrm{nmoll}^{-1}\right.$, $24 \mathrm{~h})$, or the demethylating agent $5 \mathrm{azadC}\left(2 \mu \mathrm{moll}^{-1}, 72 \mathrm{~h}\right)$, or a combination of both (cells treated with 5 azadC for $72 \mathrm{~h}$ were resuspended in fresh supplemented medium and harvested $33 \mathrm{~h}$ later. Trichostatin A treatment was applied during the last 8 or $24 \mathrm{~h}$ ), did not influence significantly methylation status of these various promoter sites (Figure $6 \mathrm{~A}$ and $\mathrm{B}$ ), indicating that $A B C B 1$ gene modulation, induced by TSA in both cell lines, does not result from alterations in the methylation status of the $A B C B 1$ promoter. Finally, although treatment with 5azadC alone induced a significant increase in $A B C B 1$ expression in H69WT cells (about 2.5-fold increase, data not shown), it did not modulate TSAinduced upregulation of $A B C B 1$ expression in H69WT. Similarly, in the H69VP drug-resistant cells, the combined treatment with TSA and 5azadC did not enhance the level of $A B C B 1$ downregulation, except for $24 \mathrm{~h}$ treatment with TSA (Figure 6C), probably in relation with the activation of a repressor of $A B C B 1$ transcription. Thus, the low level of $A B C B 1$ promoter methylation we observed in H69WT and H69VP cells, or other methylated sequences outside GC boxes and Inr element analysed, do not appear critical for TSA action on $A B C B 1$ mRNA expression in these cells containing originally a hypomethylated $A B C B 1$ promoter. It has been reported that MBD1, a protein associated with methylation-dependent repression, could also bind nonmethylated DNA (Baker and El Osta, 2004). Thus, MBD1 binding to the inverted CCAAT box $(-79$ to -75$)$ of the $A B C B 1$ promoter was evaluated in H69VP cells by ChIP using an anti-MBD1 

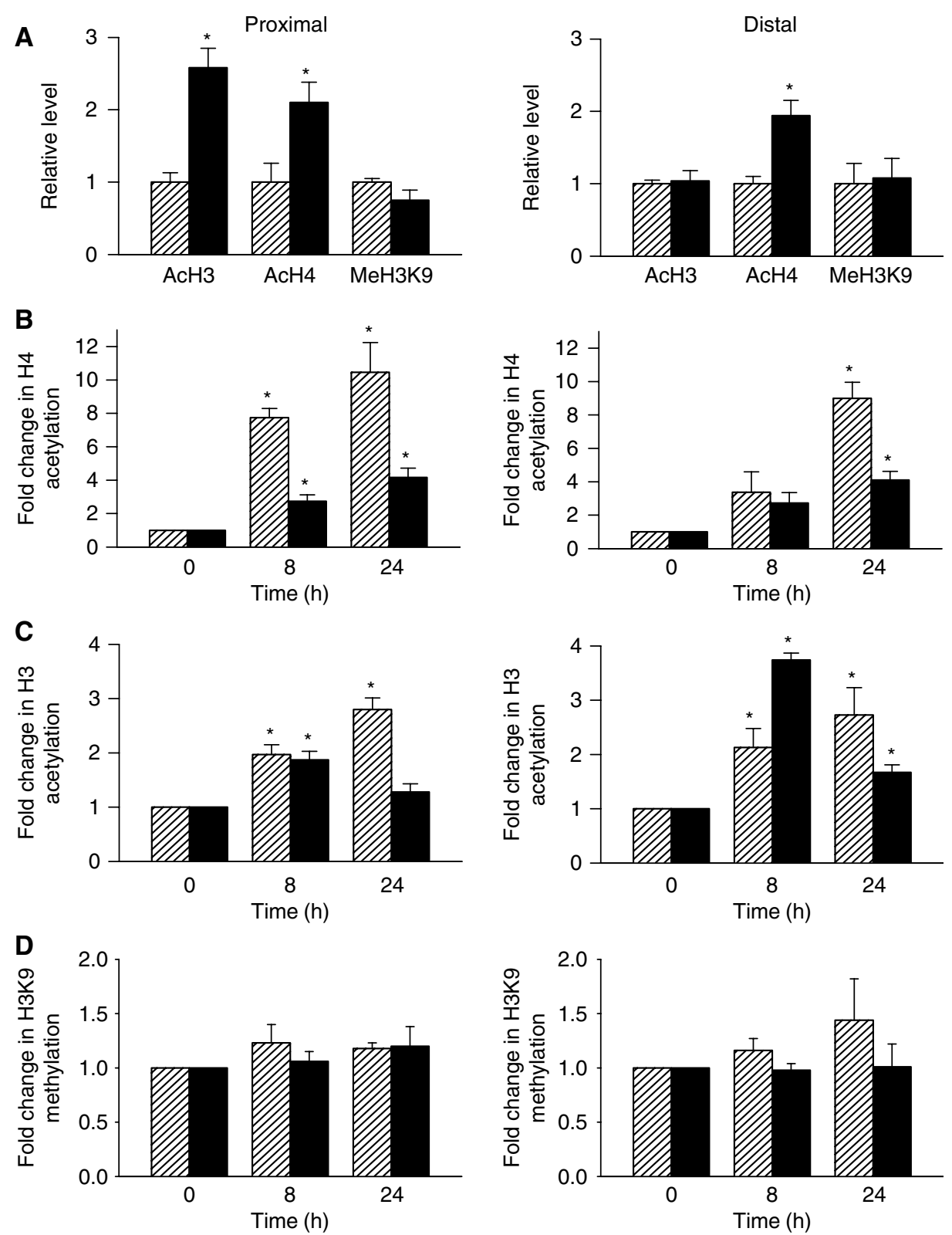

Figure 5 Trichostatin A induces differential temporal histone acetylation at the $A B C B$ / promoter level. (A) Relative level of $\mathrm{H} 3$ acetylation, $\mathrm{H} 4$ acetylation, and H3K9 dimethylation at the proximal and distal regions of the ABCB I promoter in untreated H69WT (hatched bars) and H69VP cells (black bars). Fold change in acetylated $\mathrm{H} 4(\mathbf{B})$, acetylated $\mathrm{H3}(\mathbf{C})$, and dimethylated $\mathrm{H3K} 9(\mathbf{D})$ at the proximal and distal regions of the ABCB I promoter in $\mathrm{H} 69 \mathrm{WT}$ (hatched bars) and H69VP (black bars) cells treated with TSA ( $330 \mathrm{nmol}^{-1}$, 8, and $24 \mathrm{~h}$ ). PCR amplifications of ChIP samples (mean \pm s.e.m. from three independent experiments). $* P<0.05$

antibody. Trichostatin A treatment $\left(330 \mathrm{nmoll}^{-1}, 18 \mathrm{~h}\right)$ did not induce any significant change in MBD1 recruitment on the promoter site (Figure 7A), suggesting that the $A B C B 1$ expression decrease observed in H69VP cells was not linked to a MBD1mediated methylation-independent silencing.

TSA treatment results in similar PCAF binding to $A B C B 1$ promoter CCAAT inverted box in both cell lines

Histone deacetylases inhibitors induce $A B C B 1$ transcription through the association of the NF-Y factor with the CCAAT inverted box and the PCAF HAT recruitment (Friedman et al, 2002). To determine the role of this process in the $A B C B 1$ regulations induced by TSA in $\mathrm{H} 69$ cells, the chromatin from
H69WT and H69VP cells, treated or not with $330 \mathrm{nmol} / \mathrm{LTSA}$ for $24 \mathrm{~h}$, has been immunoprecipitated by anti-PCAF antibody. The immunoprecipitated DNA was analysed by PCR using primers corresponding to the inverted CCAAT box promoter region. Before TSA treatment, PCAF binding to the $A B C B 1$ promoter appeared similar in H69WT and H69VP cells (Figure 7B). This suggests that basal $A B C B 1$ overexpression observed in H69VP cells does not result from an increased PCAF protein binding. Incubation of cells with TSA for $24 \mathrm{~h}$ resulted in an increase in PCAF recruitment in both cell lines (2- to 3 -fold increase) without any significant difference between H69WT and H69VP cells response (Figure 7C). Then PCAF recruitment occurred at the $A B C B 1$ promoter level during TSA treatment, whether this treatment resulted in an up- or downregulation of the corresponding gene. 

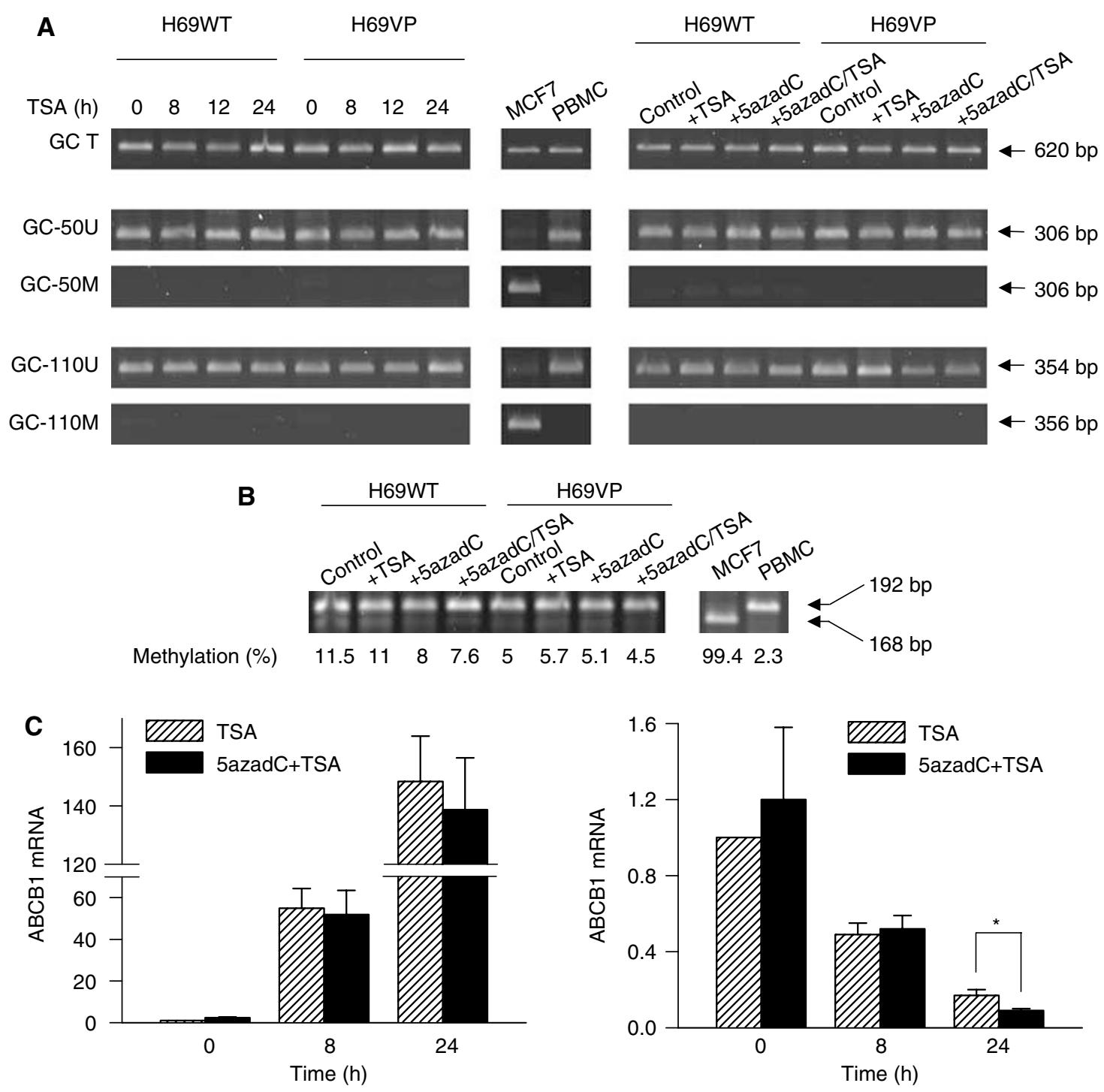

Figure 6 Trichostatin $A$ (TSA)-induced up- and downregulations of $A B C B /$ expression appear independent of $A B C B /$ promoter methylation. (A) Methylation-specific PCR of $A B C B I-50 G C$ and - IIOGC boxes. Primer sets are designed to amplify methylated $(M)$ and unmethylated $(U)$ alleles. $A$ primer set encompassing both $M$ and $U$ whole GC region $(T)$ was used as loading control. Left lane, MSP analysis in H69WT and H69VP cells treated with TSA for up to $24 \mathrm{~h}$. Right lane, MSP analysis in H69WT and H69VP cells treated with TSA for $8 \mathrm{~h}, 5$ azadC for $72 \mathrm{~h}$, or combination of both. MCF7 cells and peripheral blood mononuclear cells (PBMC) were used as positive controls for methylated and unmethylated alleles, respectively (central lane). Representative experiment from a series of three. (B) Combined bisulphite restriction analysis of the Inr ABCBI promoter region in H69WT and H69VP cells treated with TSA, 5azadC, or a combination of both. Figures represent the methylation percentages observed in the different samples (mean of two separate independent experiments). MCF7 cells and PBMC were used as positive controls for methylated and unmethylated Inr site, respectively. (C) ABCB I mRNA expression in H69WT (left) and H69VP (right) cells treated with TSA alone or in combination with 5azadC. ABCB/ expression was normalised against I8S RNA expression. Quantitation of the relative changes in $A B C B$ I expression was measured by real time RT-PCR (mean \pm s.e.m. of three independent experiments). ${ }^{*} P<0.05$.

\section{DISCUSSION}

Epigenetic mechanisms (histone acetylation, DNA methylation) have been shown to play a pivotal role in $A B C B 1$ gene expression in several tumour cell systems (El-Osta et al, 2002; Labialle et al, 2002; Scotto, 2003).

Results presented here show that HDAC inhibitors TSA and $\mathrm{NaB}$ increased $A B C B 1$ gene expression in H69WT drug-sensitive cells, but strongly inhibited its expression in H69VP drug-resistant cells at both the mRNA and protein levels. H69 cells constitutively express the $A B C C 1$ drug transporter, with an overexpression in H69VP cells. ABCC1 TATA-less gene promoter shares common regulatory elements with $A B C B 1$ (eg GC boxes, Sp1 binding site, putative AP-1 site). Interestingly, TSA also downregulated this ABCC1 gene expression in H69VP drug-resistant cells (data not shown). Thus, our results support the idea that HDAC inhibitors could modulate MDR through simultaneous inhibition of different $\mathrm{ABC}$ transporters as recently suggested for 4-phenylbutyrate (Ammerpohl et al, 2007).

Simultaneous treatments with the transcription inhibitor ActD suggested that these up- and downregulations occurred at the transcriptional level without any change in mRNA stability as reported in leukaemic cells (Yague et al, 2003). De novo protein synthesis inhibition with $\mathrm{CHX}$ did not suppress TSA-mediated $A B C B 1$ modulations, suggesting that TSA influence mainly this gene transcription directly at the chromatin level. However, as 

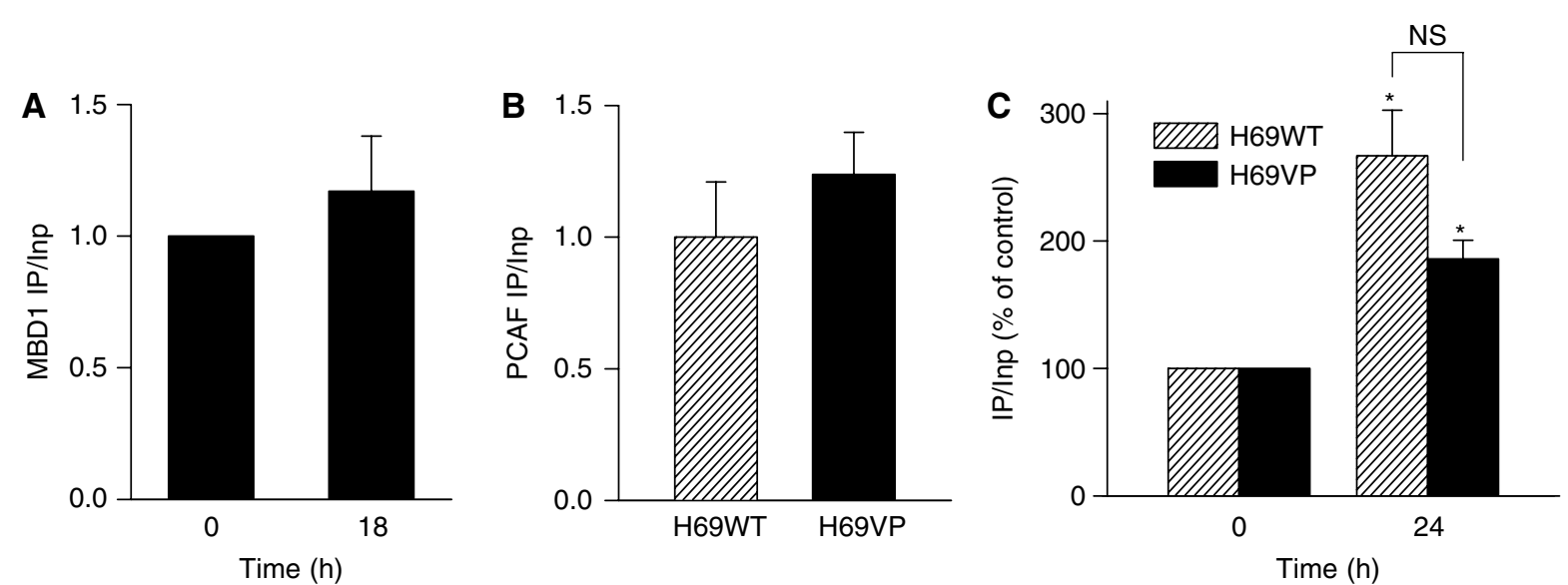

Figure 7 Trichostatin $A$ (TSA)-induced inhibition of $A B C B$ / expression in H69VP cells appears independent of MBDI and PCAF binding to the $A B C B$ I promoter CCAAT inverted box. (A) Chromatin immunoprecipitation analysis of MBDI binding in H69VP cells treated with TSA (330 nmol $\mathrm{I}^{-1}$ ) for I8 $\mathrm{h}$. (B) Chromatin immunoprecipitation analysis of PCAF binding in untreated H69WT and H69VP cells. (C) Relative changes in PCAF binding in H69WT and H69VP cells treated with TSA $\left(330 \mathrm{nmol} \mathrm{I}^{-1}\right)$ for $24 \mathrm{~h}$. *Significantly different from untreated controls. $P<0.05$ (mean \pm s.e.m. from three independent experiments).

CHX reduced the intensity of these changes, a modulation by TSA of the transcription of other genes implicated in $A B C B 1$ regulation could occur as well. Among these, WTH3 was shown to be upregulated by TSA in MCF7/Adr cells resulting in an inhibition of MDR1 expression (Tian et al, 2005). Despite a similar increase in WTH3 expression in H69VP cells, this factor may not be a good candidate for $A B C B 1$ inhibition by TSA as WTH3 is also upregulated in TSA-treated H69WT cells exhibiting an increase in $A B C B 1$ expression. These conflicting results might be related to different methylation status observed in H69 or MCF7 cells (David et al, 2004). Cycloheximide alone appeared able to increase the basal $A B C B 1$ expression in $\mathrm{H} 69$ cells. This increase, which has already been described for other genes (Keller and Kneissel, 2005), could suggest that $A B C B 1$ expression would be controlled by short-lived repressor, or that $\mathrm{CHX}$ might directly stimulate $A B C B 1$ gene transcription as reported for $\alpha-1 \mathrm{~B}$ adrenergic gene ( $\mathrm{Hu}$ and Hoffman, 1993). In drug-sensitive cells, several studies have reported an increase in $A B C B 1$ expression by HDAC inhibitors, a phenomenon we also observed in H69WT cells. For instance, $A B C B 1$ gene was overexpressed in SW620 colon carcinoma and CEM-Bcl2 cells exposed to TSA (Jin and Scotto, 1998; Baker et al, 2005), or KU812 and NB4 cells exposed to depsipeptide (Tabe et al, 2006; Yamada et al, 2006). In drug-resistant cells, HDAC inhibition also increased $A B C B 1$ expression in CEM-A7R, Kasumi-1, and Kasumi-6 cell lines (El-Osta et al, 2002; Tabe et al, 2006). On the contrary, our results showed a repression of $A B C B 1$ gene expression by TSA and $\mathrm{NaB}$. Direct inhibition of $A B C B 1$ expression by HDAC inhibitors in drug-resistant cells appeared as a relatively uncommon event, previously reported in murine L1210R cells (Castro-Galache et al, 2003).

To better understand the mechanisms of $A B C B 1$ regulation in H69 cells, we have investigated the effect of HDAC inhibition by TSA on histone post-translational modifications, focusing on $\mathrm{H} 3$ and $\mathrm{H} 4$ acetylation, and H3K9 methylation. We found that even though TSA increased global accumulation of acetylated histones, $\mathrm{H} 3$ and $\mathrm{H} 4$ acetylation displayed different temporal patterns at the $A B C B 1$ promoter level. Histone deacetylases inhibitors increase $\mathrm{H} 3$ and/or $\mathrm{H} 4$ acetylation at the promoter of activated genes such as T $\beta$ RII (Zhao et al, 2003), IAP (Hinnebusch et al, 2003), or Mn-SOD (Maehara et al, 2002). We observed the same phenomenon in H69WT drug-sensitive cells both at distal and proximal regions of the $A B C B 1$ promoter. Examining the downstream +292 to +591 region of the gene give data on the histone modification of the transcribed part of the gene and therefore on possible regulation of elongation by histone modification. Concerning the -981 to -817 region, the T-cell factor- 4 (TCF4)/ $\beta$-catenin complex has been reported as an $A B C B 1$ transcriptional activator which binds seven elements spanning the -1813 to -261 sequence of the $A B C B 1$ promoter. The -981 to -817 region harbours one of these seven TCF elements (Yamada et al, 2000). It has been recently suggested that TCF4 plays an important role in the carcinogenesis of lung cancer as demonstrated by its high expression in cancer samples (Li et al, 2005). Besides, overexpression of $\beta$-catenin reported in lung cancer and Wnt signalling pathway, which results in $\beta$-catenin stabilisation and activation, is found to be aberrantly activated in lung cancer (Mazieres et al, 2005). Hence, examining the acetylation status of the -981 to -817 region of the $A B C B 1$ promoter seemed interesting in the H69 lung carcinoma cell lines. Changes in $\mathrm{H} 3$ and $\mathrm{H} 4$ acetylation were rapid (within $8 \mathrm{~h}$ ) and directly correlated with $A B C B 1$ induction. Similar data have been reported in NB4 cells incubated with FK228 (Tabe et al, 2006), or in CEM-Bcl 2 cells treated with daunorubicin (Baker et al, 2005). In TSA-treated H69VP cells, $\mathrm{H} 4$ acetylation exhibited the same kinetics than in drug-sensitive cells, in spite of the repression of the $A B C B 1$ gene induced. Furthermore, $\mathrm{H} 3$ acetylation displayed a biphasic curve with a transient hyperacetylation followed by a decrease in this acetylation level. Interestingly, TSA-mediated decrease in $A B C B 1$ mRNA occurred rapidly after $8 \mathrm{~h}$ when both $\mathrm{H} 3$ and $\mathrm{H} 4$ displayed a hyperacetylated pattern at the gene promoter level. Similar gene inhibition by TSA in spite of $\mathrm{H} 4$ acetylation at the promoter level has already been described for PU.1 gene (Laribee and Klemsz, 2001). Several hypotheses can be proposed to explain this unexpected phenomenon: a nucleosome displacement induced by histone acetylation could result in masking of critical DNA activation sites (Laribee and Klemsz, 2001), or the gene repression could be linked to the acetylation by TSA of nonhistone proteins implicated in gene transcription (Wilson et al, 2002; Mulholland et al, 2003). In H69VP cells, after $24 \mathrm{~h}$ of TSA treatment, $\mathrm{H} 3$ acetylation decreases whereas $\mathrm{H} 4$ acetylation continues to increase. This $\mathrm{H} 3$ deacetylation cannot be explained by TSA degradation or efflux as global hyperacetylation remains high at the whole nucleus level. This decrease in acetylated H3 might be linked to nucleosomes loss instead of $\mathrm{H} 3$ deacetylation (Deckert and Struhl, 2001), but this seems rather unlikely as this loss would result in concomitant decrease in acetylated H4 level. Deacetylation following a transient hyperacetylation of $\mathrm{H} 3$ and/or 
H4 by TSA has already been described at the level of mouse mammary tumour virus and c-jun promoters (Thompson et al, 2001; Mulholland et al, 2003), and even $A B C B 1$ promoter in CEMBcl2 cells (Baker et al, 2005). Nevertheless, it should be noted that the $\mathrm{H} 3$ acetylation level observed after $24 \mathrm{~h}$ TSA in H69VP cells was always above the basal value measured in untreated cells. Thus, H3 acetylation decrease could help or maintain $A B C B 1$ silencing, but would probably not act as a starting event of the process.

In addition to histone post-translational modifications, DNA methylation is one of the mechanisms controlling $A B C B 1$ transcription with an inverse relationship between promoter $\mathrm{CpG}$ methylation and $A B C B 1$ expression (Kantharidis et al, 1997; Nakayama et al, 1998; El-Osta et al, 2002). However, as we observed promoter hypomethylation in H69WT cells, $A B C B 1$ repression in drug-sensitive cells seems independent of its promoter methylation, a phenomenon previously reported in SW620 cells (Jin and Scotto, 1998; Baker et al, 2005). In H69 cells, TSA induces up- or downregulation of $A B C B 1$ without any significant modification of its promoter methylation status, as already observed in CCRF-CEM cells (El-Osta et al, 2002). It has been reported that $A B C B 1$ activation by HDACs can only occur when its promoter is demethylated, either spontaneously or after treatment with demethylating agent 5azacytidine (El-Osta et al, 2002). In a similar way, in H69WT cells, TSA alone can induce $A B C B 1$ expression since its promoter appeared hypomethylated and simultaneous incubation with $5 \mathrm{azadC}$ did not potentiate gene expression, as observed in hypomethylated CEM-Bcl2 and SW620 cells (Baker et al, 2005). 5azadC alone induced moderate $A B C B 1$ expression suggesting either a possible further slight demethylation of an already hypomethylated $A B C B 1$ promoter (as observed by COBRA analysis of the Inr sequence), or the demethylation of the promoter of other gene(s) implicated in $A B C B 1$ activation. Our results in H69VP drug-resistant cells demonstrate that TSA could induce $A B C B 1$ silencing in a hypomethylated promoter environment. This effect could be linked to the induction of an increase in DNA methylation level as it has been reported that $\mathrm{NaB}$ was able to increase this level in several cell lines (DeHaan et al, 1986; Cosgrove and Cox, 1990). Nevertheless, our results showed that $A B C B 1$ repression by TSA in H69VP cells was not associated with a hypermethylation of its promoter at the analysed sites. Furthermore, it has been suggested that MBD1 protein could play a role in
$A B C B 1$ methylation-independent silencing (Baker and El Osta, 2004). The lack of MBD1 recruitment following TSA treatment argues against this possibility in H69VP-resistant cells.

To further elucidate possible mechanisms of TSA-mediated $A B C B 1$ regulations in $\mathrm{H} 69$ cells, the ChIP assay was performed to determine if PCAF binding to $A B C B 1$ promoter differs between drug-sensitive and drug-resistant cells and if PCAF occupancy changes following HDAC inhibition by TSA in these two cell lines. This protein, which possesses a HAT activity, can therefore activate basal or induced expression of $A B C B 1$ gene (Hu et al, 2000; Friedman et al, 2002; Tanaka et al, 2003). Moreover, $A B C B 1$ promoter is activated by PCAF overexpression (Jin and Scotto, 1998), but a direct association of PCAF with $A B C B 1$ promoter in vivo has not been previously demonstrated. Our results show that PCAF is bound to the $A B C B 1$ promoter in a similar extent in drugsensitive and drug-resistant cells and reveal similar increases in the level of bound PCAF in TSA-treated H69WT or H69VP cells. These results suggest that the levels of PCAF binding to $A B C B 1$ promoter in vivo do not correlate with gene expression level in $\mathrm{H} 69$ drugsensitive and drug-resistant cells, unlike NF-Y binding in SSC cells (Okamura et al, 2004). The increase in PCAF binding upon TSA treatment in H69WT cells fits well with previous reports on the role of this protein in $A B C B 1$ induction. However, the silencing of $A B C B 1$ gene by TSA in H69VP cells was accompanied by a similar increase in PCAF recruitment to the promoter inverted CCAAT box region. This suggests that the $A B C B 1$ gene repression induced by TSA in drug-resistant cells occurs independently of PCAF binding.

Taken together, our data provide evidence that HDAC inhibition can result in differential regulation of the $A B C B 1$ gene according to the resistance status of the SCLC H69 cells (Figure 8). Although a definite unique regulatory mechanism cannot be drawn from these results, they suggest that these regulations occur at a transcriptional level. The fact that $A B C B 1$ will be up- or downregulated in H69 cells appears independent of the methylation of the $A B C B 1$ $-50 \mathrm{GC},-110 \mathrm{GC}$, and Inr promoter sites, and of MBD1 and PCAF binding, but is associated to different temporal patterns of histone acetylation at the $A B C B 1$ promoter level. Whereas the CCAAT inverted box plays a pivotal role in $A B C B 1$ upregulation by HDAC inhibitors, it seems that their repressive effect on this gene expression originates outside this element. Although TSA is not in

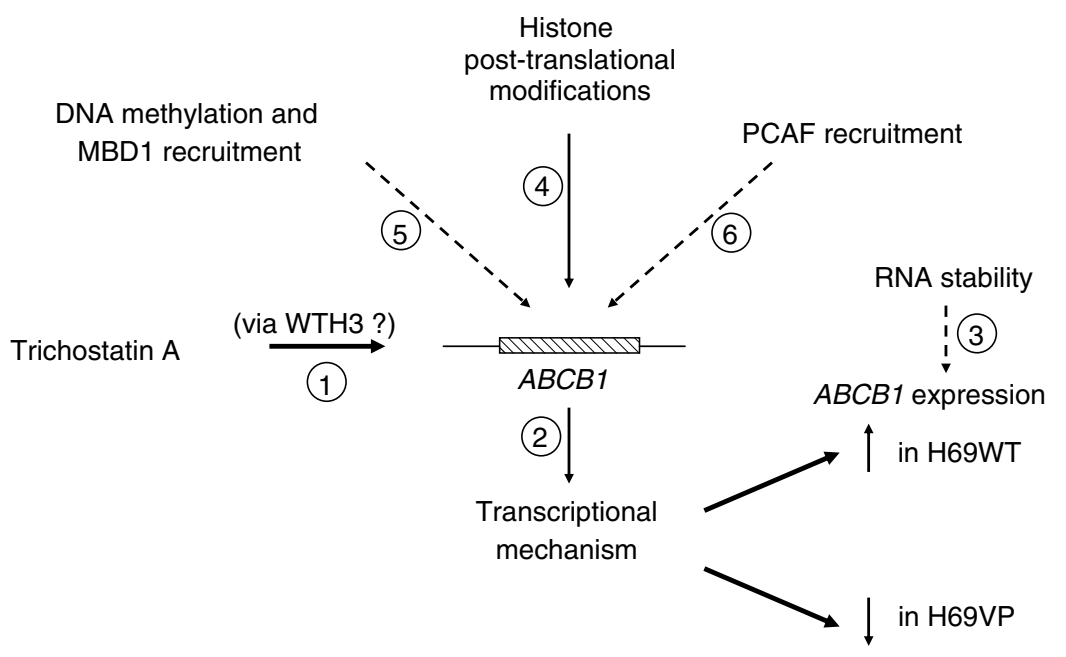

Figure 8 Pathways summary: trichostatin A modulates $A B C B$ I gene expression in H69 cells (increase in H69WT cells but decrease in H69VP cells). This differential modulation occurs both through a direct action on chromatin and through changes in regulatory factors expression (I). Among these, WTH3 does not play a key role. This modulation occurs through transcriptional mechanisms (2) and is not linked to alterations in RNA stability (3). It is concomitant with differential histone acetylation patterns at the $A B C B$ I promoter (4), but appears independent of DNA methylation and MBDI (5) or PCAF recruitment (6) on CCAAT inverted box. Dashed lines represent pathways that cannot explain the differential regulation of ABCBI expression in $\mathrm{H} 69 \mathrm{WT}$ and $\mathrm{H} 69 \mathrm{VP}$ cells. 
clinical trials, this study supports the idea that HDAC inhibitors might be chemosensitising agents and promising drugs for combinatorial treatments with classical chemotherapeutic drugs. The characterisation by reporter constructs of the promoter sequences required for these up- and downregulations of $A B C B 1$ in H69 cells is currently under investigation in our laboratory to identify trans-regulatory factors mediating this differential TSA effect.

Most drug-resistant lung cancers overexpress both P-gp and MRP1 proteins (Triller et al, 2006). H69VP-resistant cells exhibit upregulation of both MDR proteins, somehow reflecting situations commonly seen in clinic. In this sense, the choice of this cell model seems appropriate. However, ABCB1 promoter of H69VP cells is constitutively strongly hypomethylated, and the downregulation of $A B C B 1$ expression by HDAC inhibition could require such low level of DNA methylation in $A B C B 1$ promoter. Indeed, we have previously shown that $A B C B 1$ expression remains unchanged after TSA treatment of the multidrug-resistant human ovarian adenocarcinoma cell line OV1/VCR, in which $A B C B 1$ promoter is slightly

\section{REFERENCES}

Alvelo-Ceron D, Niu L, Collart DG (2000) Growth regulation of human variant histone genes and acetylation of the encoded proteins. Mol Biol Rep 27: $61-71$

Ammerpohl O, Trauzold A, Schniewind B, Griep U, Pilarsky C, Grutzmann R, Saeger HD, Janssen O, Sipos B, Kloppel G, Kalthoff H (2007) Complementary effect of HDAC inhibitor 4-PB on gap junction communication and cellular export mechanisms support restoration of chemosensitivity of PDAC cells. Br J Cancer 96: 73-81

Baker E, El Osta A (2004) MDR1, chemotherapy and chromatin remodeling. Cancer Biol Ther 3: 819-824

Baker EK, Johnstone RW, Zalcberg JR, El-Osta A (2005) Epigenetic changes to the MDR1 locus in response to chemotherapeutic drugs. Oncogene 24: $8061-8075$

Berger SL (2002) Histone modifications in transcriptional regulation. Curr Opin Genet Dev 12: $142-148$

Brock I, Hipfner D, Nielsen B, Jensen P, Deeley R, Cole S, Sehested M (1995) Sequential coexpression of the multidrug resistance genes MRP and mdr1 and their products in VP-16 (etoposide)-selected H69 small cell lung cancer cells. Cancer Res 55: 459-462

Castro-Galache MD, Ferragut JA, Barbera VM, Martin-Orozco E, GonzalezRos JM, Garcia-Morales P, Saceda M (2003) Susceptibility of multidrug resistance tumor cells to apoptosis induction by histone deacetylase inhibitors. Int J Cancer 104: $579-586$

Cosgrove DE, Cox GS (1990) Effects of sodium butyrate and 5-azacytidine on DNA methylation in human tumor cell lines: variable response to drug treatment and withdrawal. Biochim Biophys Acta 1087: 80-86

David GL, Yegnasubramanian S, Kumar A, Marchi VL, De Marzo AM, Lin $\mathrm{X}$, Nelson WG (2004) MDR1 promoter hypermethylation in MCF-7 human breast cancer cells: changes in chromatin structure induced by treatment with 5-aza-cytidine. Cancer Biol Ther 3: 540-548

Deckert J, Struhl K (2001) Histone acetylation at promoters is differentially affected by specific activators and repressors. Mol Cell Biol 21: $2726-2735$

DeHaan JP, Gevers W, Parker MI (1986) Effects of sodium butyrate on the synthesis and methylation of DNA in normal cells and their transformed counterparts. Cancer Res 46: 713-716

El-Khoury V, Gomez D, Liautaud-Roger F, Trussardi-Regnier A, Dufer J (2004) Effects of the histone deacetylase inhibitor trichostatin A on nuclear texture and c-jun gene expression in drug-sensitive and drugresistant human H69 lung carcinoma cells. Cytometry A 62: 109-117

El-Osta A, Kantharidis P, Zalcberg JR, Wolffe AP (2002) Precipitous release of methyl-CpG binding protein 2 and histone deacetylase 1 from the methylated human multidrug resistance gene (MDR1) on activation. Mol Cell Biol 22: $1844-1857$

Friedman D, Hu Z, Kolb EA, Gorfajn B, Scotto KW (2002) Ecteinascidin743 inhibits activated but not constitutive transcription. Cancer Res 62 $3377-3381$

Gottesman MM (2002) Mechanisms of cancer drug resistance. Annu Rev Med 53: 615-627 hypermethylated compared to its sensitive IGROV1 counterpart (Yatouji et al, 2007). Further methylation analysis on different cell lines and clinical samples is required to clarify the relevancy of basal methylation status of $A B C B 1$ promoter on $A B C B 1$ repression by HDAC inhibitors.

Despite these limitations, this unique cellular model, which can display HDAC-mediated up- or downregulation of $A B C B 1$ gene according to resistance status, appears therefore useful for effective design of agents to reverse MDR in cancer patients.

\section{ACKNOWLEDGEMENTS}

This work was supported by grants from ARERS and Comités départementaux de la Marne et des Ardennes de la Ligue Française contre le Cancer. Victoria El-Khoury was the recipient of a fellowship from ARERS. We thank Professor Maxwell Sehested for H69VP cell line.
Grunstein M (1997) Histone acetylation in chromatin structure and transcription. Nature 389: 349-352

Hinnebusch BF, Henderson JW, Siddique A, Malo MS, Zhang W, Abedrapo MA, Hodin RA (2003) Transcriptional activation of the enterocyte differentiation marker intestinal alkaline phosphatase is associated with changes in the acetylation state of histone $\mathrm{H} 3$ at a specific site within its promoter region in vitro. J Gastrointest Surg 7: 237-244

Holzmayer T, Hilsenbeck S, Von Hoff D, Robinson I (1992) Clinical correlation of MDR1 (P-glycoprotein) expression in ovarian and small cell lung carcinoma. J Natl Cancer Inst 84: 1486-1491

$\mathrm{Hu}$ Z, Jin S, Scotto KW (2000) Transcriptional activation of the MDR1 gene by UV irradiation. Role of NF-Y and Sp1. J Biol Chem 275: 2979-2985

$\mathrm{Hu}$ ZW, Hoffman BB (1993) Cycloheximide induces the alpha 1B adrenergic receptor gene by activation of transcription in DDT1 MF-2 smooth muscle cells. Mol Pharmacol 44: 1105-1112

Jin S, Scotto KW (1998) Transcriptional regulation of the MDR1 gene by histone acetyltransferase and deacetylase is mediated by NF-Y. Mol Cell Biol 18: 4377-4384

Kantharidis P, El Osta A, De Silva M, Wall DM, Hu XF, Slater A (1997) Altered methylation of the human MDR1 promoter is associated with acquired multidrug-resistance. Clin Cancer Res 3: 2025-2032

Keller H, Kneissel M (2005) SOST is a target gene for PTH in bone. Bone 37: $148-158$

Labialle S, Gayet L, Marthinet E, Rigal D, Baggetto LG (2002) Transcriptional regulators of the human multidrug resistance 1 gene: recent views. Biochem Pharmacol 64: 943 -948

Laribee RN, Klemsz MJ (2001) Loss of PU.1 expression following inhibition of histone deacetylases. J Immunol 167: 5160-5166

Li CY, Wang Y, Cui ZS, Wang EH (2005) Expression of T cell factor-4 in non-small-cell lung cancer. Chin Med J 118: 136-140

Longley DB, Johnston PG (2005) Molecular mechanisms of drug resistance. J Pathol 205: 275-292

Maehara K, Uedawa N, Isobe KI (2002) Effects of histone acetylation on transcriptional regulation of manganese superoxide dismutase gene. Biochem Biophys Res Commun 295: 187-192

Mazieres J, He B, You L, Xu Z, Jablons DM (2005) Wnt signaling in lung cancer. Cancer Lett 222: 1-10

Mulholland NM, Soeth E, Smith CL (2003) Inhibition of MMTV transcription by HDAC inhibitors occurs independent of changes in chromatin remodeling and increased histone acetylation. Oncogene 22: $4807-4848$

Nakayama M, Wada M, Harada T, Nagayama J, Kusaba H, Ohshima K (1998) Hypomethylation status of CpG sites at the promoter region and overexpression of the human MDR1 gene in acute myeloid leukemias. Blood 92: 4296-4307

Okamura H, Yoshida K, Sasaki E, Morimoto H, Haneji T (2004) Transcription factor NF-Y regulates MDR1 expression through binding to inverted CCAAT sequence in drug-resistant human squamous carcinoma cells. Int J Oncol 25: 1031-1037 
Poupon MF, Arvelo F, Goguel AF, Bourgeois Y, Jacrot M, Hanania N, Arriagada R, Le Chevalier T (1993) Response of small-cell lung cancer xenografts to chemotherapy: multidrug resistance and direct clinical correlates. J Natl Cancer Inst 85: 2023-2029

Savaraj N, Wu C, Xu R, Lampidis T, Lai S, Donnelly E, Solomon J, Feun L (1997) Multidrug-resistant gene expression in small-cell lung cancer. Am J Clin Oncol 20: 398-403

Scotto KW (2003) Transcriptional regulation of ABC drug transporters. Oncogene 22: 7496-7511

Tabe Y, Konopleva M, Contractor R, Munsell M, Schober WD, Jin L, Tsutsumi-Ishii Y, Nagaoka I, Igari J, Andreeff M (2006) Up-regulation of MDR1 and induction of doxorubicin resistance by histone deacetylase inhibitor depsipeptide (FK228) and ATRA in acute promyelocytic leukemia cells. Blood 107: 1546-1554

Tanaka H, Ohshima N, Ikenoya M, Komori K, Katoh F, Hidaka H (2003) HMN-176, an active metabolite of the synthetic antitumor agent HMN214, restores chemosensitivity to multidrug-resistant cells by targeting the transcription factor NF-Y. Cancer Res 63: 6942-6947

Thompson S, Clayton AL, Mahadevan LC (2001) Independent dynamic regulation of histone phosphorylation and acetylation during immediateearly gene induction. Mol Cell 8: 1231-1241

Tian K, Jurukovski V, Wang XP, Kaplan MH, Xu H (2005) Epigenetic regulation of WTH3 in primary and cultured drug-resistant breast cancer cells. Cancer Res 65: 10024-10031

Triller N, Korosec P, Kern I, Kosnik M, Debeljak A (2006) Multidrug resistance in small cell lung cancer: expression of P-glycoprotein, multidrug resistance protein 1 and lung resistance protein in chemonaive patients and in relapsed disease. Lung Cancer 54: 235-240

Tsurutani J, Soda H, Oka M, Suenaga M, Doi S, Nakamura Y, Nakatomi K, Shiozawa K, Yamada Y, Kamihira S, Kohno S (2003) Antiproliferative effects of the histone deacetylase inhibitor FR901228 on small-cell lung cancer lines and drug-resistant sublines. Int J Cancer 104: 238-242

Wilson MA, Ricci AR, Deroo BJ, Archer TK (2002) The histone deacetylase inhibitor trichostatin A blocks progesterone receptor-mediated transactivation of the mouse mammary tumor virus promoter in vivo. J Biol Chem 277: $15171-15181$

Xiong Z, Laird PW (1997) COBRA: a sensitive and quantitative DNA methylation assay. Nucleic Acids Res 25: 2532-2534

Yague E, Armesilla AL, Harrison G, Elliott J, Sardini A, Higgins CF, Raguz S (2003) P-glycoprotein (MDR1) expression in leukemic cells is regulated at two distinct steps, mRNA stabilization and translational initiation. J Biol Chem 278: $10344-10352$

Yamada H, Arakawa Y, Saito S, Agawa M, Kano Y, Horiguchi-Yamada J (2006) Depsipeptide-resistant KU812 cells show reversible P-glycoprotein expression, hyper-acetylated histones, and modulated gene expression profile. Leuk Res 30: 723-734

Yamada T, Takaoka AS, Hayashi R, Maruyama K, Maesawa C, Ochiai A, Hirohashi S (2000) Transactivation of the multidrug resistance 1 gene by T-cell factor 4/beta-catenin complex in early colorectal carcinogenesis. Cancer Res 60: $4761-4766$

Yatouji S, El-Khoury V, Trentesaux C, Trussardi-Regnier A, Benabid R, Bontems F, Dufer J (2007) Differential modulation of nuclear texture, histone acetylation, and MDR1 gene expression in human drug-sensitive and -resistant OV1 cell lines. Int J Oncol 30: 1003-1009

Yoo CB, Jones PA (2006) Epigenetic therapy of cancer: past, present and future. Nat Rev Drug Discov 5: 37-50

Zhao S, Venkatasubbarao K, Li S, Freeman JW (2003) Requirement of a specific Sp1 site for histone deacetylase-mediated repression of transforming growth factor beta Type II receptor expression in human pancreatic cancer cells. Cancer Res 63: 2624-2630 